\title{
A rare case of utero-vaginal prolapse seen at third trimester: case report and review of literature
}

\author{
Adebayo Awoniyi ${ }^{1}$, Aloy Okechukwu Ugwu' ${ }^{1 *}$, Sunusi Rimi Garba ${ }^{1}$, \\ Nneoma Kwemtochukwu Aniugwu², Augustine Egba', Olabisi Olanrewaju', \\ Oluwaseun Emmanuel Familusi ${ }^{1}$, Olayemi Emmanuel Olumakinwa ${ }^{1}$, Kehinde Okunade ${ }^{3}$
}

\begin{abstract}
${ }^{1}$ Department of Obstetrics and Gynaecology, ${ }^{2}$ Department of Medicine, Lagos University Teaching Hospital, Lagos, Nigeria

${ }^{3}$ Department of Obstetrics and Gynaecology, Lagos University Teaching Hospital, College of medicine, University of Lagos, Laos, Nigeria
\end{abstract}

Received: 07 June 2021

Accepted: 05 July 2021

*Correspondence:

Dr. Aloy Okechukwu Ugwu,

E-mail: okeyugwu92@gmail.com

Copyright: () the author(s), publisher and licensee Medip Academy. This is an open-access article distributed under the terms of the Creative Commons Attribution Non-Commercial License, which permits unrestricted non-commercial use, distribution, and reproduction in any medium, provided the original work is properly cited.

\section{ABSTRACT}

Pelvic organ prolapse (POP) is an infrequent cause of morbidity in pregnancy. We presented a case of stage three uterovaginal prolapse that was first noticed in the third trimester. Management of POP is individualized and its determined by the severity of the symptoms, stage of the prolapse, gestational age, patient's desire and expertise of the gynaecologist. Different options of management have been proposed ranging from conservative to laparoscopy, hysterectomy in women with no desire for further child bearing. Vaginal delivery is an option; however, most obstetricians opt for elective caesarean section at term.

Keywords: Pelvic organ prolapses, Conservative management, Caesarean section, Lagos

\section{INTRODUCTION}

Genital prolapse occurs when pelvic organs herniates or protrudes beyond its anatomical confines. ${ }^{1}$ The primary pathology is mostly due to dysfunction of pelvic floor which occurs in 30-50\% of aged woman half of which are multiparous. ${ }^{1}$ Uterovaginal prolapse occurs when there is weakness in any of the structures that contribute to the pelvic organ support such as ligaments, fascia, muscles and posterior angulation of the vagina., ${ }^{1,2}$ Pelvic organ prolapse (POP) in pregnancy include those in which diagnosis was made prior to pregnancy which expectedly resolves spontaneously in second trimester when the uterus rises to become an abdominal organ, it gives minimal or no symptom as pregnancy advances while those that develop in during pregnancy most times occurs in the third trimester, the prevalence of which varies from 1 in 10,000 to 1 in 15,000 .
The occurrence of POP in pregnancy has been hypothesized to be most likely from physiological changes in pregnancy, increase hormone production which synergistically results in softening, stretching and relaxation of pelvic soft tissues in a woman with other predisposing risk factors. Its associated with cervical edema, cervical dystocia in labour and prolonged obstructed labour because of inadequate cervical dilatation. $^{2,3}$

\section{CASE REPORT}

A 41 years unbooked multiparous woman who was referred to our facility at 33 weeks' gestational age on account of worsening uterovaginal prolapse noticed two weeks ago at the referring hospital. She booked for antenatal care at the referring facility at 8 weeks' gestational age, her booking weight was $87 \mathrm{~kg}$, her height 
was $160 \mathrm{~cm}$ and her BMI was $33.9 \mathrm{kgm}^{-2}$. Other booking parameters were essentially normal. Pelvic examination done at booking revealed no abnormal finding, no evidence of prolapse. She had two uncomplicated spontaneous vaginal deliveries in 2017 and 2019, when she was delivered of male neonates weighing $3.6 \mathrm{~kg}$ and $3.9 \mathrm{~kg}$ respectively.

Pregnancy, labour and puerperium were uneventful. On presentation to our facility, she was a young woman in no obvious distress, afebrile, anicteric, not pale, not dehydrated. Her abdominal examination revealed a singleton fetus in longitudinal lie and cephalic presentation, symphysiofundal height of 30 centimetres. Obstetrics ultrasound done confirmed the above findings with estimated fetal weight of $1.7 \mathrm{~kg}$. Pelvic examination revealed a stage three uterovaginal prolapse $(\mathrm{Aa}+3, \mathrm{Ap}+3$, $\mathrm{Ba}+6, \mathrm{Bp}+6, \mathrm{C}+6, \mathrm{D}+2$, gh 4.5, pb 2, tvl 9), no ulceration seen. The prolapse was worse on walking around, standing upright or at any attempt of lifting any object. She was counselled on the diagnosis and management options, following which she was admitted into the lying-in ward for bed rest in a moderately trendelenburg position so as to minimize cervical edema and uterine descent. Good perineal hygiene was ensured all through the period of admission.

She subsequently had a spontaneous onset of labour and rupture of fetal membrane at 37 weeks' gestational age. However, she had poor progress of labour secondary to cervical dystocia, for which she had emergency caesarean section. She was delivered of a female neonate weighing $3.3 \mathrm{~kg}$. She opted for vaginal pessary insertion as a conservative management option.

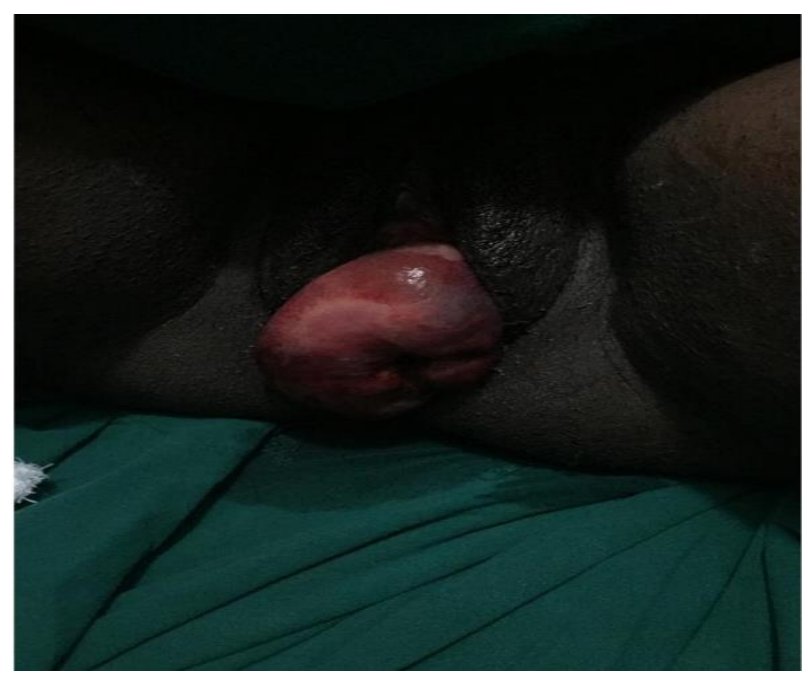

Figure 1: Prolapsed pregnant uterus.

\section{DISCUSSION}

Genital prolapse is a non-life threatening condition that affects a woman's quality of life, its effect is more on the morbidity than mortality as it impacts on her social, emotional and coital function. ${ }^{4}$ Risk factors for POP include pregnancy, multiparity, menopause, previous history of macrosomia, difficult deliveries, unsupervised/prolonged second stage of labour, instrumental deliveries, congenital weakness in pelvic floor muscles such as in some connective tissue disorders while the precipitating factors may include chronic cough, chronic constipation, lifting of heavy objects, large intraabdominal tumors, ascites and obesity. ${ }^{4,5}$

Women with genital prolapse could present in several ways, this clinical presentation may be due to direct or indirect symptoms. Direct symptoms include vaginal fullness or bulge (which can be reducible or irreducible), low back pain with dragging sensation or pelvic heaviness or discomfort. Indirect symptoms include urinary symptoms (such as urinary retention, dysuria, incomplete bladder emptying, recurrent urinary tract infection, urgency, stress or incontinence following coital activity), difficult or incomplete defecation, post defecation soiling or even sexual dysfunction (dyspareunia, vaginal laxity). ${ }^{4-7}$ Some may also present with abnormal vaginal discharge, bleeding and ulceration of the most dependent part of the prolapse which is usually attributed to venous congestion..$^{5-7}$ Any woman presenting with any of these symptoms need to be evaluated and treated appropriately to avoid development of complications some of which include abnormal keratinization of the vagina, decubital ulcers, hypertrophy of the cervix, obstructive effect on urinary tract and incarceration of the prolapse

In addition, POP, although a rare occurrence in pregnancy, the clinical presentation during pregnancy depends on whether the prolapse predates pregnancy or it was first recognized in the index pregnancy. For those whose prolapse predates pregnancy, it most often resolves during pregnancy, but recurs post-delivery. The most common are those whose symptoms are first recognised in pregnancy, they usually present in third trimester, the symptom may disappear following labour and delivery. ${ }^{1,2,6}$ Our patient presented at 33 weeks' gestational age with stage three uterovaginal prolapse. In pregnancy, pelvic organ prolapse can lead to some complications such as spontaneous miscarriage, premature rupture of membrane, preterm labour, prematurity, recurrent urinary tract infection, acute urinary retention, cervical dystocia in labour, poor progress of labour, genital tract injuries, obstructed labour and postpartum haemorrhage. Our patient had poor labour progress secondary to cervical dystocia.

Management of pelvic organ prolapse is multidisciplinary, involving the obstetrician, psychologist, dedicated nurse midwife, anaesthetists and a neonatologist. It should be individualized, the considerations include, gestational age, severity of the symptoms, patients' wish, expertise available. ${ }^{1-3,7,8}$ The options of management include conservative management as was done in our patient, this include admission for bed rest, good perineal hygiene, positional changes such as trendelenburg position. Other options include laparoscopic suspension or even use of 
pessary. ${ }^{2,3,7}$ Hysterectomy during caesarean section is an option for women who has completed child bearing. $3,7,8$ Decision regarding route of delivery is mainly on obstetrics indications as vaginal delivery is safe in women with prolapse, however, there may be need for emergency caesarean section in cases of cervical dystocia. ${ }^{1-3}$ Some authors advocate for elective caesarean section at term especially when the prolapsed uterus cannot be reduced. ${ }^{1-3}$

\section{CONCLUSION}

Uterovaginal prolapse is very rare in pregnant women, early recognition and prompt individualized treatment is required to improve her quality of life, and to prevent the morbidity that may arise.

Funding: No funding sources

Conflict of interest: None declared

Ethical approval: Not required

\section{REFERENCES}

1. Tsikouras P, Dafopoulos A, Vrachnis N, Iliodromiti $\mathrm{Z}$, Bouchlariotou S, Pinidis $\mathrm{P}$, et al. Uterine prolapse in pregnancy: risk factors, complications and management. J Matern Fetal Neonatal Med. 2014;27(3):297-302.
2. Zeng C, Yang F, Wu C, Zhu J, Guan X, Liu J. Uterine Prolapse in Pregnancy: Two Cases Report and Literature Review. Case Rep Obstet Gynecol. 2018;1805153.

3. Jiang Y, Zhang Y, Ma C, Wang Q, Xu C, Donovan C, et al. H7N9 not only endanger human health but also hit stock marketing. Adv Dis Control Prev. 2017;2(1):1-7.

4. Rabiu KA, Adewunmi AA, Badmus SA, Akinola OI, Akinlus FM. Pelvic Organ Prolapse in Lagos, Nigeria. Nigerian J Clinic Med. 2009: 2(2); 11-17.

5. Oraekwe OI, Udensi MA, Nwachukwu KC, Okali UK. Genital prolapse: A 5-year review at Federal Medical Centre Umuahia, Southeastern Nigeria. Niger Med J. 2016;57(5):286-9.

6. Jelovsek JE, Maher C, Barber MD. Pelvic organ prolapse. Lancet. 2007;369(9566):1027-38.

7. Ojiyi E, Anolue F, Ejekunle S, Nzewuihe A, Okeudo $\mathrm{C}$, et al. Emergency Contraception: Awareness, Perception and Practice among Female Undergraduates in Imo State University, Southeastern Nigeria. Ann Med Health Sci Res. 2014;4(6):904-9.

8. Okeke TC, Ani VC, Ezenyeaku CC, Ikeako LC, Enwereji JO, Ekwuazi K. An audit of uterovaginal prolapse in Enugu, Southeast Nigeria. Am J Clin Med Res. 2013;1:23-5.

Cite this article as: Awoniyi A, Ugwu AO, Garba SR, Aniugwu NK, Egba A, Olanrewaju O, et al. A rare case of utero-vaginal prolapse seen at third trimester: case report and review of literature. Int J Reprod Contracept Obstet Gynecol 2021;10:3212-4. 